\title{
The distribution of ammonia-oxidizing betaproteobacteria in stands of Black mangroves (Avicennia germinans)
}

\author{
Hendrikus J. Laanbroek ${ }^{1,2,3}{ }^{*}$, Rosalinde M. Keijzer ${ }^{1}$, Jos T. A. Verhoeven ${ }^{2,3}$ and Dennis F. Whigham ${ }^{3}$ \\ 1 Department of Microbial Ecology, Netherlands Institute of Ecology, Wageningen, Netherlands \\ 2 Institute of Environmental Biology, Utrecht University, Utrecht, Netherlands \\ ${ }^{3}$ Smithsonian Environmental Research Station, Edgewater, MD, USA
}

\section{Edited by:}

Svetlana N. Dedysh, Russian

Academy of Sciences, Russia

\section{Reviewed by:}

Chris Francis, Stanford University, USA

Anne Bernhard, Connecticut College, USA

\section{*Correspondence:}

Hendrikus J. Laanbroek, Department of Microbial Ecology, Netherlands Institute of Ecology (NIOO-KNAW), P.O. Box 50, 6700 AB Wageningen, Netherlands.

e-mail: r.laanbroek@nioo.knaw.nt
The distribution of species of aerobic chemolitho-autotrophic microorganisms such as ammonia-oxidizing bacteria are governed by $\mathrm{pH}$, salinity, and temperature as well as the availability of oxygen, ammonium, carbon dioxide, and other inorganic elements required for growth. Impounded mangrove forests in the Indian River Lagoon, a coastal estuary on the east coast of Florida, are dominated by mangroves, especially stands of Black mangrove (Avicennia germinans) that differ in the size and density of individual plants. In March 2009, the management of one impoundment was changed to a regime of pumping estuarine water into the impoundment at critical times of the year to eliminate breeding sites for noxious insects. We collected soil samples in three different Black mangrove habitats before and after the change in management to determine the impacts of the altered hydrologic regimes on the distribution of $16 \mathrm{~s}$ rRNA genes belonging to ammonia-oxidizing betaproteobacteria ( $\beta$-AOB). We also sampled soils in an adjacent impoundment in which there had not been any hydrologic alteration. At the level of $97 \%$ mutual similarity in the $16 \mathrm{~s}$ rRNA gene, 13 different operational taxonomic units were identified; the majority related to the lineages of Nitrosomonas marina (45\% of the total clones), Nitrosomonas sp. Nm143 (23\%), and Nitrosospira cluster 1 (19\%). Long-term summer flooding of the impoundment in 2009, after initiation of the pumping regime, reduced the percentage of $N$. marina by half between 2008 and 2010 in favor of the two other major lineages and the potential ammoniaoxidizing activity decreased by an average of $73 \%$. Higher interstitial salinities, probably due to a prolonged winter drought, had a significant effect on the composition of the $\beta$ AOB in March 2009 compared to March 2008: Nitrosomonas sp. Nm143 was replaced by Nitrosospira cluster 1 as the second most important lineage. There were small, but significant differences in the bacterial communities between the flooded and non-flooded impoundments. There were also differences in the community composition of the bacteria in the three Black mangrove habitats. N. marina was most dominant in all three habitats, but was partly replaced by Nitrosospira cluster 1 in sites dominated by sparsely distributed trees and by Nitrosomonas sp. Nm143 in sites characterized by taller, more densely distributed Black mangrove trees.

Keywords: ammonia oxidation, betaproteobacteria, mangroves, flooding

\section{INTRODUCTION}

Aerobic ammonia-oxidizing bacteria (AOB) and archaea play an important role in the global nitrogen cycle by converting ammonium to nitrite (Kowalchuk and Stephen, 2001; Schleper and Nicol, 2010). Nitrite can then be further oxidized to nitrate by nitriteoxidizing bacteria or used as an electron acceptor in a large number of microbial and chemical redox reactions. The diversity of aerobic $A O B$ is limited to a small number of genera within the classes of the beta- and gammaproteobacteria (Kowalchuk and Stephen, 2001) but, based on studies applying the phylogenetic 16s rRNA gene and the functional amoA gene, the ammonia-oxidizing betaproteobacteria $(\beta-\mathrm{AOB})$ are widely distributed and occur in many habitats. The studies that have been reported also demonstrated that their abundance is influenced by the prevailing environmental conditions. On the basis of the $16 \mathrm{~S}$ rRNA gene, for example, it was shown that sequences belonging to the Nitrosomonas oligotropha lineage dominated in the more frequently flooded and actively nitrifying habitats in tidal freshwater wetlands, whereas sequences related to the Nitrosospira lineage were more abundant in habitats that were less frequently flooded and less active in relation to ammonium oxidation (Laanbroek and Speksnijder, 2008).

Mangroves are tree-dominated intertidal wetlands along tropical and subtropical coastlines with a specialized flora adapted to waterlogged and saline conditions. Mangroves are often found in distinct zones of different species and stature (Feller et al., 2003; Lovelock and Feller, 2003) with temperature, salinity, frequency of tidal inundation, soil texture, degree of soil anoxia, 
$\mathrm{pH}$, predation, and competition being factors that account for the zonation (Alongi, 2008). Nutrient availability also varies spatially in mangroves and plays a key role in their size and distribution (Feller et al., 2003). Research on the abundance and diversity of AOB in mangroves has been limited to studies of polluted and rehabilitated mangrove sediments in Southeast Asia (Wickramasinghe et al., 2009; Cao et al., 2011b; Li et al., 2011). Hence, there is little information about the distribution and abundance of AOB in mangroves at the global scale and even less is known about the abundance and distribution of $\mathrm{AOB}$ in relation to spatial variations of mangrove species and the factors that control their distribution and growth.

Almost all mangroves in the Indian River Lagoon of Florida were impounded, primarily between 1954 and 1970, to control noxious salt-marsh mosquitoes and biting midges (Rey and Kain, 1991; Brockmeyer et al., 1997). In later years culverts were placed in the dikes around the impoundments to restore limited tidal exchange and in a few impoundments, tropical storms destroyed sections of the dikes resulting in increased tidal exchange with the estuary.

In 2008 we initiated a study to determine the effects of altered hydrologic conditions on ecological characteristics of mangroves. The study was made possible because the St. Lucie County Mosquito Control and Coastal Management Services ${ }^{1}$ had developed plans to alter the hydrology of one impoundment by pumping water into it during the season when nuisance insects were most problematic. We hypothesized that the hydrological changes would give rise to changes in ecological processes in the mangroves, including the growth rates of mangroves, the rates of nitrogen cycling, and the community composition of the AOB.

Here we report on the diversity of ammonia-oxidizing betaproteobacteria before, during, and after the changes in hydrology in three different Black mangrove habitats, i.e., locations with dwarf, sparse, and dense trees. We tested the hypotheses that changes in soil characteristics associated with habitat type and managementdirected flooding for insect control would alter the community structure of the ammonia-oxidizing betaproteobacteria and thereby the rates of potential ammonia-oxidizing activity.

\section{MATERIALS AND METHODS \\ STUDY LOCATIONS}

Soil samples were collected in March 2008, 2009, and 2010 in two mangrove-dominated impoundments $\left(27^{\circ} 33^{\prime} \mathrm{N}, 80^{\circ} 19^{\prime} \mathrm{W}\right)$ in the Indian River Lagoon, a coastal sub-estuary, located on North Hutchinson Island, St. Lucie County, FL, USA. The climatic conditions and subsoil characteristics of the study area have been previously described (Stringer, 2010; Stringer et al., 2010). Most of the mangroves in the Indian River Lagoon were impounded between 1954 and 1970 to control numbers of salt-marsh mosquitoes and biting midges. Following the establishment of the impoundments, most of the mangroves died. Subsequently, breaches in the dikes as a result of hurricanes and the installation of culverts through the dikes resulted in the restoration of tidal exchange between the impoundments and the estuary. Since the restoration of tidal

\footnotetext{
${ }^{1}$ http://www.stlucieco.gov/mosquito/index.htm
}

exchange, mangrove-dominated vegetation has re-established in the impoundments (Brockmeyer et al., 1997). Avicennia germinans L. (Black mangrove) was the dominant species in both impoundments (Feller et al., 2003; Lovelock and Feller, 2003). However, the heights of the mangroves differed. The tallest mangroves occurred in the wettest habitats and at the upland-wetland border, while the shortest trees occurred in areas where the soil salinities were very high (18). Other abundant species throughout the impoundments were Conocarpus erectus (Button bush), Batis maritima (Saltwort), Salicornia virginica (Glasswort), and Salicornia bigelovii (Dwarf glasswort).

The March 2008 sampling represented conditions in the two impoundments prior to the pumping of estuarine water into Impoundment 24. In March 2009, rotational impoundment management (i.e., seasonal flooding by pumping water into the impoundment from the lagoon) was initiated and it coincided with our soil sampling. During the period of rotational pumping of estuarine water (March-October) much of the impoundment had standing water; at other times, water levels were allowed to fluctuate naturally through the culverts. Due to the changes in management practice initiated in March 2009, groundwater levels changed substantially in Impoundment 24. Water levels also changed in Impoundment 23 (Stringer, 2010) demonstrating that the impoundments, which are immediately adjacent to each other, were hydrologically connected by groundwater that flows beneath the dike that separated them. Changes in groundwater levels were greatest in Impoundment 24, but were evident throughout Impoundment 23, with the magnitude of the changes diminishing with distance within Impoundment 23 from Impoundment 24 (M. Rains, pers. comm.).

The soil samples that were collected for the analysis of the diversity of $\beta$-AOB were obtained at sites within each impoundment that had been the focus of earlier experiments (Feller et al., 2003; Whigham et al., 2009). All sampled sites were within $500 \mathrm{~m}$ of the dike between both impoundments and they were dominated by $A$. germinans L. (Black mangrove). One of the habitats sampled was referred to as "dwarf Black mangrove" or "dwarf" (Feller et al., 2003; Lovelock and Feller, 2003) because average tree height was less than $1 \mathrm{~m}$ and tree density was low resulting in less than $30 \%$ canopy coverage. Another Black mangrove-dominated habitat was located between the areas dominated by dwarf trees and wetter habitats that had taller trees. We refer to this habitat as "sparse Black mangrove" or "sparse." Tree height in the sparse habitat averaged $1.8 \mathrm{~m}$ and tree density resulted in a canopy coverage that ranged from 30 to $80 \%$. The third Black mangrovedominated habitat, hereafter called "dense Black mangrove" or "dense," had trees that averaged $3.6 \mathrm{~m}$ in height and the tree density resulted in a canopy coverage of greater than $80 \%$. Within each impoundment, we selected five locations in each of the three habitats resulting in a total of 30 locations where soil samples were collected.

\section{SOIL COLLECTIONS}

In the March 2008, 2009, and 2010 sampling periods, three soil cores $(3.9 \mathrm{~cm}$ diameter and $10 \mathrm{~cm}$ long) were collected at each of the 30 sites. The sample locations were within 1-m of a Black mangrove that was being monitored for growth and leaf nitrogen 
content. Samples were collected with an aluminum tube that was sharpened at one end. The cores were immediately sealed at both ends with rubber stoppers and transported to the laboratory. One of the cores was used for removal of pore water that was analyzed for salinity, and $\mathrm{pH}$. The top $10-\mathrm{cm}$ of the two other cores were combined and thoroughly mixed by hand and subsequently sub-sampled for the determination of moisture content, for measurements of potential rates of nitrification, and for the analysis of the community structure of ammonia-oxidizing betaproteobacteria $(\beta$-AOB). Samples for the genetic analyses of the $\beta$-AOB were freeze-dried and stored until further analyses.

\section{DETERMINATION OF POTENTIAL AMMONIA-OXIDIZING ACTIVITIES}

To estimate the numbers of active ammonia-oxidizing cells in the soil samples, potential ammonia-oxidizing activities (PAAs) were determined in slurries of $20 \mathrm{~g}$ fresh weight soil mixed with $50 \mathrm{ml}$ of mineral medium containing ammonium at a final concentration of $1 \mathrm{mM}$, according to the protocol of Belser and Mays (1980), as modified by Verhagen and Laanbroek (1991). Salinities of the mineral media were adapted to the pore water salinity of each individual sample. The linear production of nitrite plus nitrate over time under optimal conditions of substrate, $\mathrm{pH}$, and temperature was taken as a measure of the potential rate of ammonium oxidation. Measurements were performed within $16 \mathrm{~h}$ after collection of the soil samples and the rates were followed for $6 \mathrm{~h}$ with $90 \mathrm{~min}$ sampling intervals.

\section{DNA ISOLATION}

Environmental DNA was extracted from the $0.5 \mathrm{~g}$ freeze-dried soil samples. The samples were homogenized by vortexing with $1 \mathrm{ml}$ cetyltrimethylammonium bromide (CTAB) buffer (Zhou et al., 1996) and $0.5 \mathrm{~g}$ sterilized zirconia-silica beads (diameter $0.1 \mathrm{~mm}$ ). The homogenized samples were subsequently subjected to disruption by bead-beating at a $5.0-\mathrm{m} / \mathrm{s}$ rotation for $60 \mathrm{~s}$. After the addition of $5 \mu \mathrm{l}$ proteinase $\mathrm{K}(20 \mathrm{mg} / \mathrm{ml})$, the samples were incubated for $30 \mathrm{~min}$ at $37^{\circ} \mathrm{C}$, and then vortexed after $15 \mathrm{~min}$. After the addition of $150 \mu \mathrm{l}$ of a $20 \%$ SDS solution, the samples were incubated for $1 \mathrm{~h}$ at $65^{\circ} \mathrm{C}$ in a Thermoblock apparatus and vortexed every 15-20 min. After centrifugation at $10,000 \times g$ for $10 \mathrm{~min}, 600 \mu \mathrm{l}$ of supernatant was collected in $2-\mathrm{ml}$ screw-cap tubes. The rest of the sample was re-extracted with $450 \mu \mathrm{l}$ CTAB buffer and $50 \mu \mathrm{l}$ of a $20 \%$ SDS solution, vortexed for $10 \mathrm{~s}$, incubated for $10 \mathrm{~min}$ at $65^{\circ} \mathrm{C}$, and centrifuged at $6,000 \times g$ for $10 \mathrm{~min}$. Again, $600 \mu \mathrm{l}$ was collected, added to the previously extracted supernatant, mixed with $1 \mathrm{ml}$ phenol-chloroform-isoamyl alcohol solution (25:24:1, $\mathrm{vol} / \mathrm{vol} / \mathrm{vol}$ ), and centrifuged at $6,000 \times g$ for $10 \mathrm{~min}$. One milliliter of supernatant was collected and placed into a new screw-cup tube containing $700 \mu \mathrm{l}$ isopropanol, and the tube was incubated for $1 \mathrm{~h}$ at $24^{\circ} \mathrm{C}$. After $20 \mathrm{~min}$ of centrifugation at $15,000 \times \mathrm{g}$, the isopropanol was decanted and the pellet was resuspended and washed with $1 \mathrm{ml} 70 \%$ cold ethanol. This was followed by $5 \mathrm{~min}$ of centrifugation at $15,000 \times g$, decantation of the ethanol, drying of the pellet under vacuum centrifugation, and finally, resuspension in $100 \mu l$ water (Sigma). Quantification was done with 2- $\mu$ l DNA samples and a ND-1000 apparatus (Nanodrop Technology, Wilmington, DE, USA). DNA could not be obtained from four soil samples. These samples were all from Impoundment 23 in different years and mangrove habitats: one sample was from the zone with dwarf Black mangrove trees; three were from the "dense" habitat.

\section{PCR AND CONSTRUCTION OF CLONE LIBRARIES}

Extracted DNA was amplified by nested procedure using two 16s rRNA gene primer sets specific for the majority of the betaproteobacterial $\mathrm{AOB}$, i.e., the $\beta \mathrm{AMO} 161 \mathrm{f}$ and $\beta \mathrm{AMO} 1301 \mathrm{r}$ primer set of McCaig et al. (1994) and the CTO189f and CTO654r primer set of Kowalchuk et al. (1997). One hundred nanograms of purified DNA was used as template for a $50-\mu l$ PCR mixture containing $1 \times \mathrm{Mg}$-free buffer (Invitrogen Corp., Carlsbad, CA, USA), $0.5 \mu \mathrm{M}$ of each primer, $200 \mu \mathrm{M}$ of each deoxynucleotide triphosphate, $1.75 \mathrm{mM} \mathrm{MgCl}_{2}, 400 \mathrm{ng} / \mu \mathrm{l}$ bovine serum albumin, $1.25 \mathrm{U}$ GoTaq Hot Start Polymerase (Promega). The thermocycling program for both steps consisted of 2 min of denaturation at $95^{\circ} \mathrm{C}$ followed by 35 cycles of $30 \mathrm{~s}$ of denaturation at $95^{\circ} \mathrm{C} ; 30 \mathrm{~s}$ of specific annealing at $59^{\circ} \mathrm{C}\left(\beta \mathrm{AMO}\right.$ primer set) or at $57^{\circ} \mathrm{C}$ (CTO primer set) and $45 \mathrm{~s}$ of elongation at $72^{\circ} \mathrm{C} ; 5 \mathrm{~min}$ of final elongation was performed for all reactions. Nested amplifications of 25 cycles were performed with the primer set CTO189f and CTO654r on 1:100 dilutions of PCR products from the $\beta A M O$ primer set. All reactions were verified by UV illumination of $1 \%$ agarose gels stained in a gel red or ethidium bromide solution.

Polymerase chain reaction fragments were ligated into the pGEM T-vector system (Promega Corporation, Madison, WI, USA) and transformed into JM109 competent E. coli cells (Promega) according to the manufacturers' instructions. Transformed colonies were screened for inserts of the correct size by PCR. In total 90 clone libraries were created comprising $8-32$ clones each. The number of clones was based on the number of bands detected by provisional DGGE analyses of the nested PCR products. Representative clones of the libraries were amplified with vector primers T7 and SP6 and PCR products were tested by standard preparative agarose gel electrophoresis. To ensure sequence read without ambiguities, vector products were sequenced with sufficient overlap of sequencing reads using the T7 and SP6 vector primers (Promega). Sequencing reactions were performed by Macrogen, Amsterdam, the Netherlands.

\section{SEOUENCE ANALYSES}

Sequences were aligned and checked for chimeras using Sequencher 4.1 (Gene Codes Corporation, Ann Arbor, MI, USA). The resulting contigs were visually inspected and ambiguities manually resolved. Low quality contigs were removed from the dataset. After removing sequences of insufficient length or quality, the remaining 844 sequences were further analyzed. The aligned sequences were clustered in operational taxonomic units (OTUs) with the cluster program of MOTHUR software version 1.18.1 (Schloss et al., 2009). In addition, MOTHUR was also used for establishing rarefaction curves and group (i.e., OTU) representatives. OTUs at the level of $97 \%$ mutual similarity in their 16S rRNA gene sequences $(418 \mathrm{bp})$ were chosen for further analyses. Sequence identification of the OTU-representatives was done by the BLASTN facility from the National Center for Biotechnology Information ${ }^{2}$. The partial 16SrRNA gene sequences

${ }^{2}$ http://www.ncbi.nlm.nih.gov/ 
were submitted to the GenBank database under accession numbers JQ725556-JQ726359.

Analysis of similarity (ANOSIM) between communities of $\beta$ AOB obtained from different impoundments, years, and mangrove habitats was done with the PRIMER software version 5.2.9 (Primer-E, Plymouth, UK). The same software was used for nonparametric multi-dimensional scaling of the $\beta$-AOB communities and for linking the community distribution to the measured environmental parameters (BIOENV).

\section{STATISTICAL ANALYSES}

The values for the PAAs obtained for the different impoundments, sampling years, and mangrove habitats were analyzed with the STATISTICA software version 10 (StatSoft, Inc., Tulsa, OK, USA). A non-parametric Spearman rank correlation analysis between the potential ammonia oxidation activities and other soil characteristics was performed with the same software package.

\section{RESULTS}

\section{SOIL MOISTURE CONTENT, PORE WATER SALINITY, AND pH}

Soil moisture content in the three habitats in 2010 was significantly higher than the moisture content measured in 2009 (Figures 1A,B; ANOVA on log-transformed data: $F=4.01, p=0.0223)$. There were no significant differences in soil moisture between 2008 and 2009 or between 2008 and 2010. There were no significant differences in soil moisture between the two impoundments but there were significant habitat differences (ANOVA on log-transformed data: $F=29.12, p=0.0000$ ); with increasing moisture in soils from the dwarf habitat compared to soils from sparse and dense habitats, respectively (Figure 1).

Pore water salinity differed significantly between years with significant higher values in 2009 (Figures 1C,D; Kruskal-Wallis non-parametric ANOVA: $H=48.7758, p=0.0000)$. Pore water salinity did not differ significantly between impoundments or the three habitats (Figures 1C,D).

Pore water $\mathrm{pH}$ differed between years with significantly lower values in 2010 after the estuarine water was pumped into Impoundment 24 (Figures 1E,F; ANOVA: $F=10.32, p=0.0001$ ). Again, there were no significant differences between impoundments, but $\mathrm{pH}$ differed across the three habitats (ANOVA on log-transformed data: $F=29.12, p=0.0000$ ) with significantly lower values in the dense mangrove habitat.

Matching the soil characteristics of the three mangrove habitat types with the community compositions of the AOB resulted in Spearman Rank correlations of $0.028,0.011$, and -0.034 for soil moisture content, salinity, and pore water $\mathrm{pH}$, respectively.
A
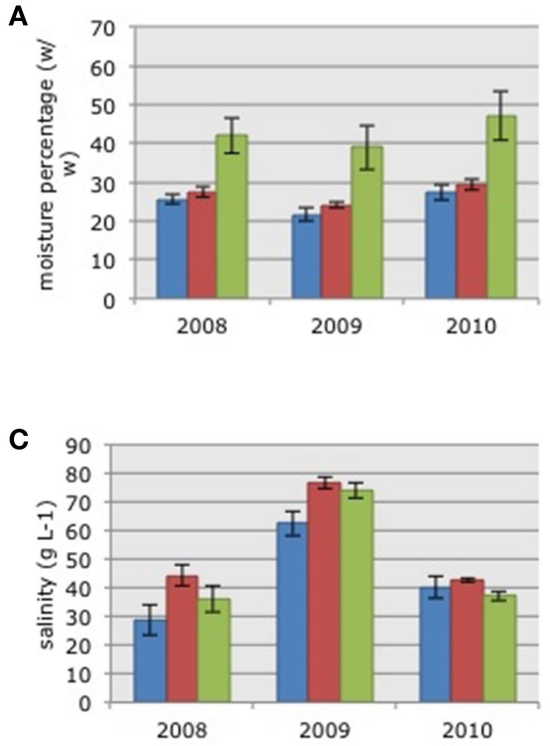

$\mathbf{E}$

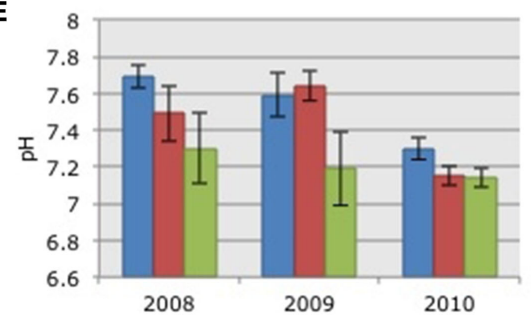

B

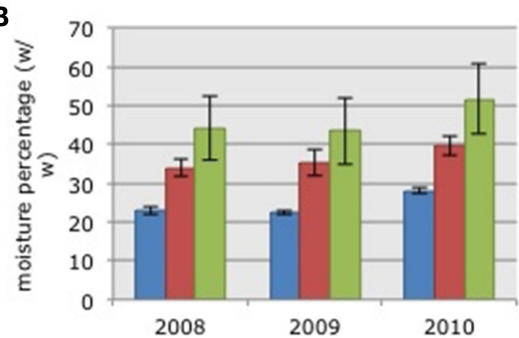

D

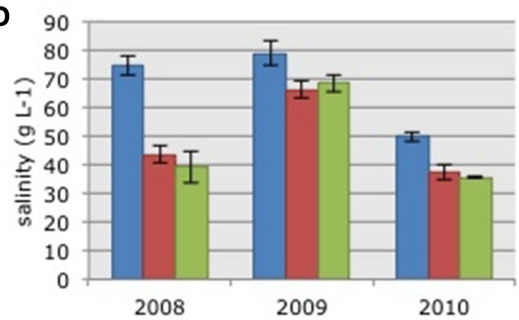

$\mathbf{F}$

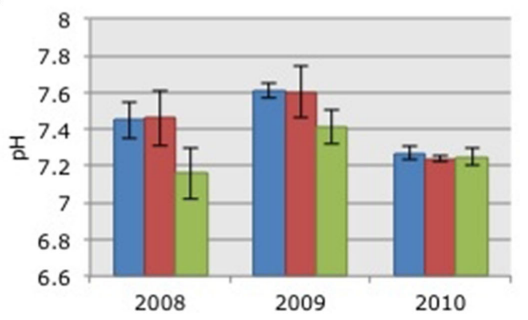

FIGURE 1 |Average soil moisture content $(A, B)$, pore water salinity $(C, D)$, and pore water $p H(E, F)$ in the samples collected in the three habitats in impoundments $23(\mathbf{A}, \mathbf{C}, \mathbf{E})$ and $24(\mathbf{B}, \mathbf{D}, \mathbf{F})$. Mangrove habitats are indicated by different colors: Blue = dwarf, red = sparse, and green = dense; SE in brackets. 


\section{POTENTIAL AMMONIA-OXIDIZING ACTIVITIES}

The activity of potential AOB declined significantly (KruskalWallis non-parametric ANOVA: $H=19.5664, p=0.0001)$ between 2008 and 2009 (Figure 2). Activity levels were lowest in 2010 but the differences between 2009 and 2010 were not significant. PAAs were not significantly different between impoundments or habitats. Testing the relationship between PAAs and the three habitats yielded a Spearman Rank correlation of 0.108 .

\section{MICROBIAL DIVERSITY}

Based on $97 \%$ mutual similarity between the 16S rRNA genes (418 bp), the 844 qualified sequences could be classified into
13 different OTUs. Due to differences in sequence quality the numbers of approved clones differed among impoundments, sampling years, and mangrove habitats (Table 1). Accounting for $45 \%$ of the total clones, OTU01 was the most numerous OTU and had the highest relative numbers in Impoundment 24, the dwarf habitat and in 2008 (Figures 3-5). With 23\% of the total, OTU04 was the second most numerous and had the highest relative abundances in Impoundment 24 and the dense habitat. Its relative abundances were similar in 2008 and 2010 and lower in 2009. The third most important OTU was OTU06 with 19\% of the total clones. The relatively abundance of OTU06 was lowest in Impoundment 23 and in 2008 and much higher in the sparse

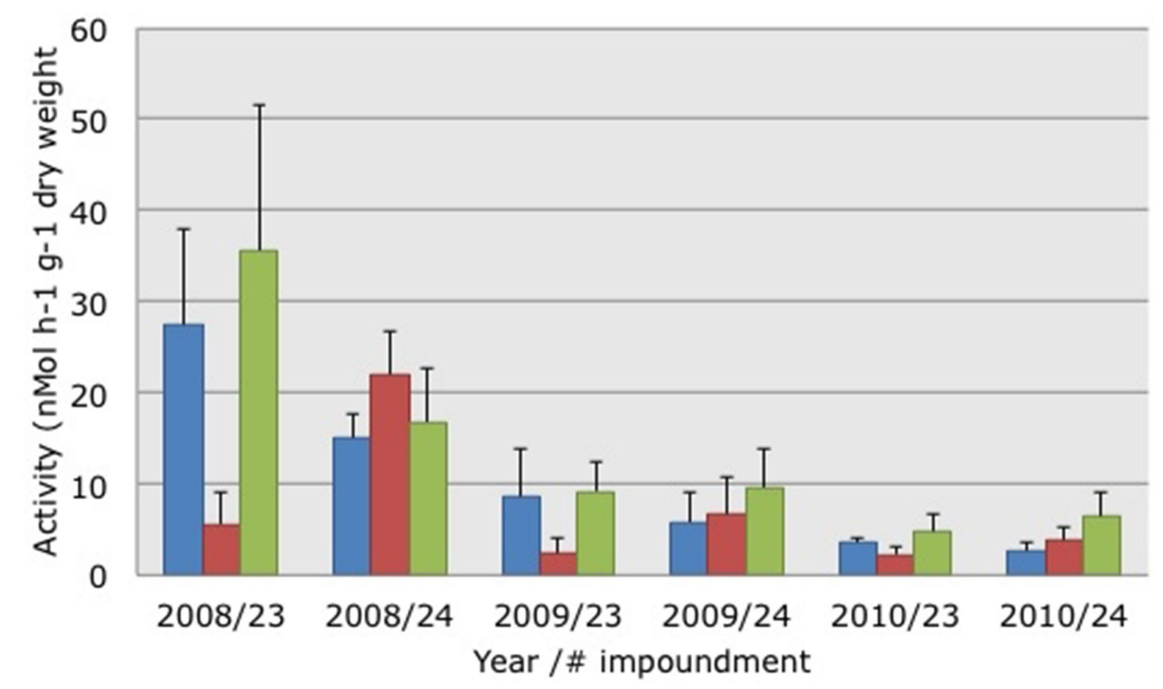

FIGURE 2 | Average potential ammonia-oxidizing activities measured in soil suspensions collected from three different habitats characterized by dwarf (blue bars), sparse (red bars), or dense (green bars) Avicennia germinans. Soils were collected in March 2008, 2009, and 2010 in impoundments 23 and 24 in the Indian River Lagoon, Florida. SE are presented in brackets.

Table 1 | Distribution of clones related to ammonia-oxidizing betaproteobacteria over the different operational taxonomic units (OTUs), impoundments, sampling years, and Black mangrove habitats.

\begin{tabular}{|c|c|c|c|c|c|c|c|c|}
\hline OTU & \multicolumn{2}{|c|}{ Impoundment } & \multicolumn{3}{|c|}{ Sampling years } & \multicolumn{3}{|c|}{ Black mangrove habitat } \\
\hline 02 & 5 & 12 & 11 & 3 & 3 & 7 & 9 & 1 \\
\hline 03 & 44 & 18 & 6 & 35 & 21 & 20 & 33 & 9 \\
\hline 04 & 72 & 121 & 76 & 41 & 76 & 25 & 59 & 109 \\
\hline 06 & 80 & 77 & 29 & 71 & 57 & 12 & 101 & 44 \\
\hline 07 & 1 & 3 & 2 & 1 & 1 & 0 & 2 & 2 \\
\hline 08 & 4 & 2 & 0 & 4 & 2 & 3 & 2 & 1 \\
\hline 09 & 8 & 1 & 0 & 9 & 0 & 8 & 0 & 1 \\
\hline 10 & 3 & 2 & 1 & 4 & 0 & 3 & 0 & 2 \\
\hline 11 & 1 & 0 & 0 & 0 & 1 & 0 & 0 & 1 \\
\hline
\end{tabular}



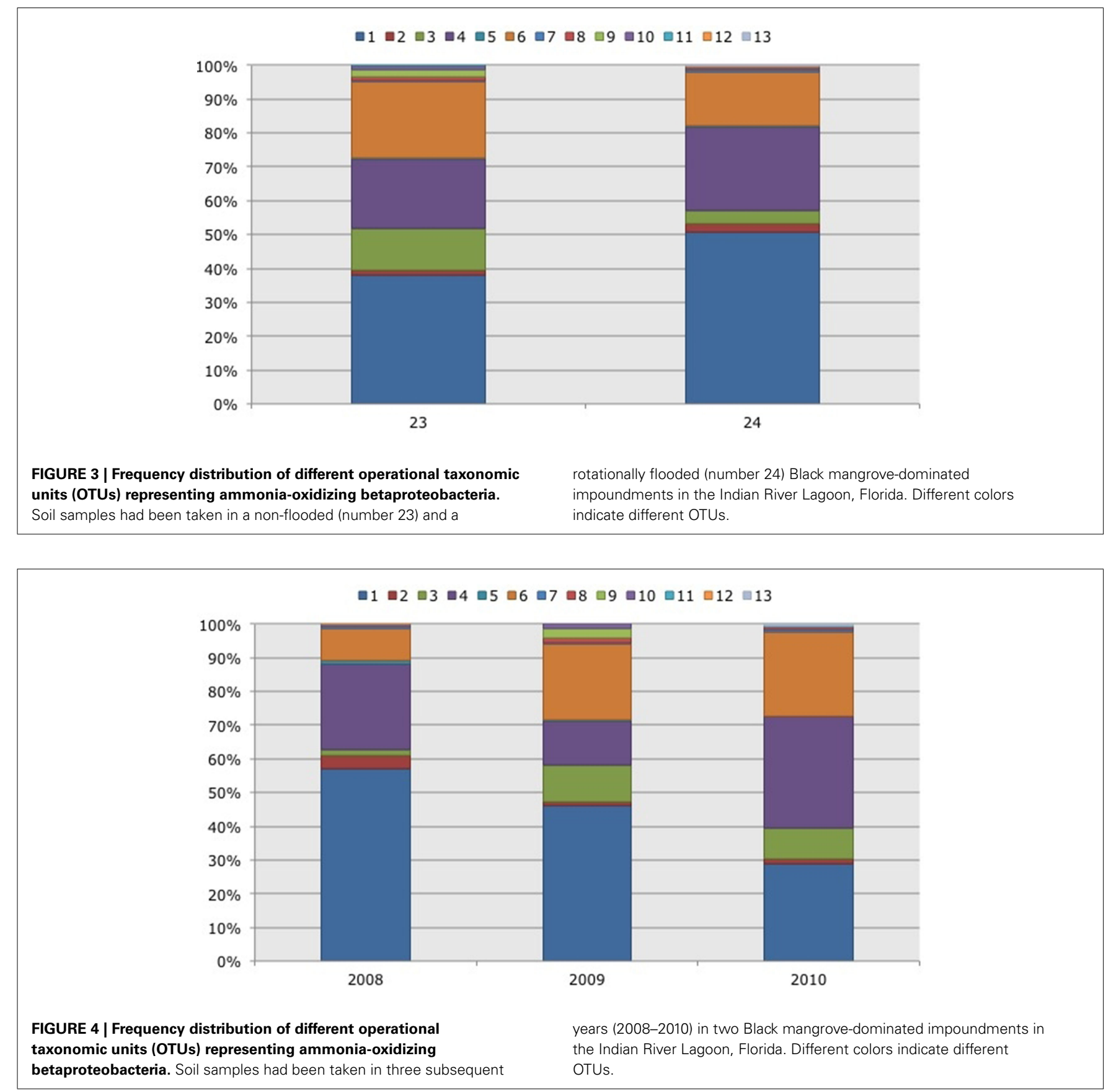

habitat. The relative abundances of the other OTUs were much lower and with the exception of OTU02 and OTU03, the minor OTUs were often absent in replicate samples of the impoundments, sampling years and habitats (Table 1).

With three exceptions, the OTUs were present in both impoundments (Table 1). OTU01 contributed most (i.e., 34\% of all OTUs) to the dissimilarities between both impoundments. OTU06 and OTU04 added 25 and 23\%, respectively to these dissimilarities, while the other OTUs were less important for the dissimilarity between the impoundments. The major OTUs were present in all years (Table1). Some minor OTUs were only enumerated in one of the years. Figure 4 shows the frequency distributions of the OTUs for the three years. With $35 \%$ of the total OTUs on average, OTU01 contributed most to the dissimilarities between the years. In addition, OTU04 and OTU06 accounted each for $25 \%$ on average, to the dissimilarities between the years with OTU04 being most important for dissimilarities between 2008 and 2010 and OTU06 between 2008 and 2009 and between 2009 and 2010. The dwarf and sparse habitats did not contain unique OTUs (Table 1). OTU01 was most abundant in the dwarf habitat samples whereas OTU06 and OTU04 had the highest relative abundances in the sparse and dense habitats, respectively (Figure 5). Of all 


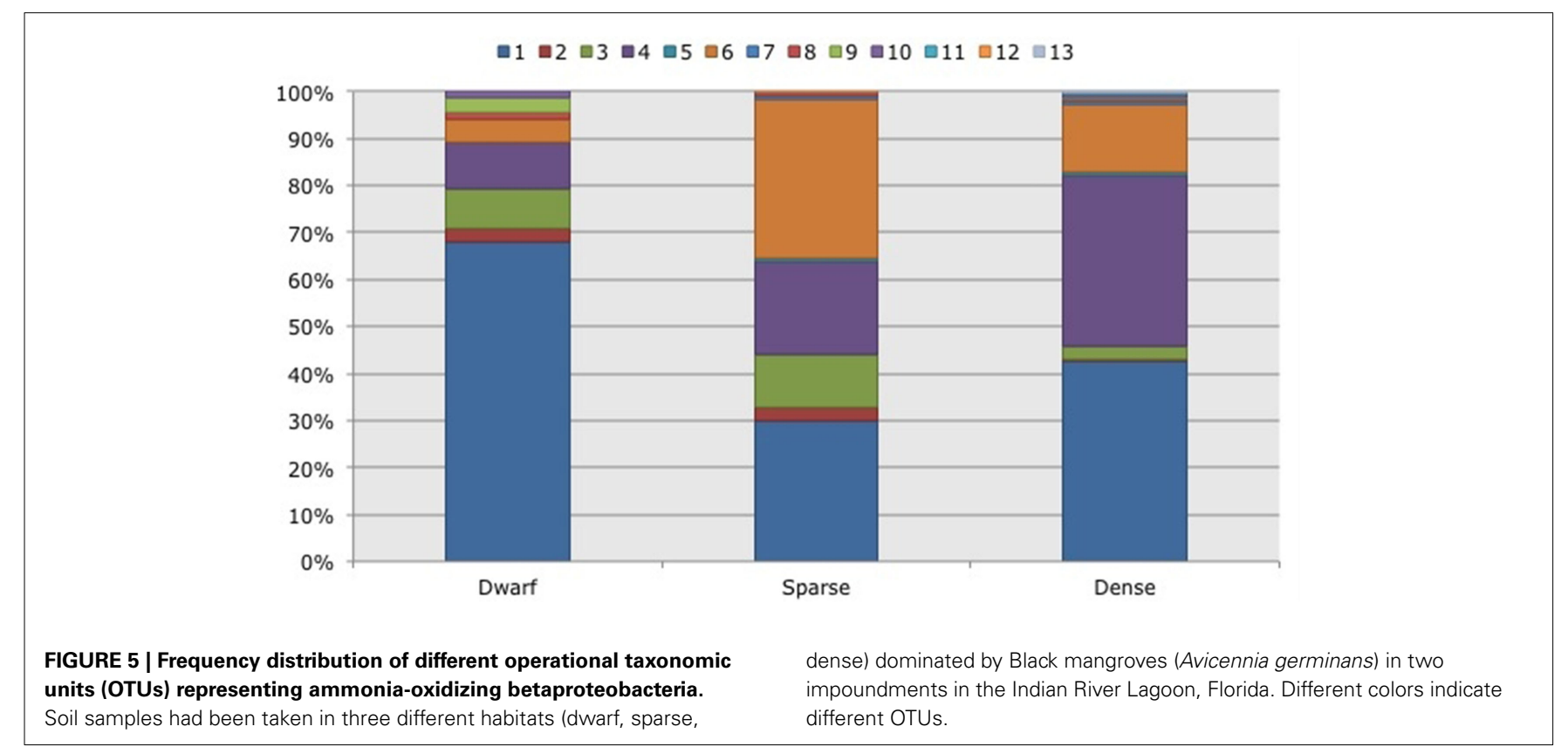

OTUs, OTU01 contributed the most to differences between the dwarf and sparse habitats and between the dwarf and dense habitats (38\% both). OTU06 was the second most abundant OTU that contributed to the differences between the dwarf and sparse habitats $(27 \%)$ and OTU04 also contributed to differences between the dwarf and dense habitats (29\%). OTU01, OTU04, and OTU06 contributed equally to the dissimilarity between the sparse and dense habitats $(29,30$, and $26 \%$, respectively).

Sequences of the clones being representative for the different OTUs according to the MOTHUR analysis showed close relationship with uncultured clones originating from mostly estuarine and marine habitats (Table 2). Exceptions were the closest relative of OTU01 that were found in a saline wetland in Chile and OTU09 and OTU10 that were encountered in nitrifying bioreactors. All OTUs were similar to uncultured clones at a level of at least $97 \%$. The number of lineages of $\beta$-AOB to which the OTUs belonged was rather limited. Only the lineages of Nitrosomonas aestuarii/Nitrosomonas marina, Nitrosomonas sp. Nm143, Nitrosomonas europaea, and Nitrosospira emerged from the search. OTUs belonging to the $N$. aestuarii/N. marina lineage, further referred as $N$. marina lineage, were by far the most numerous (Table 2), followed by OTUs identified as being related to Nitrosomonas sp. Nm143 and Nitrosospira lineages. Only 14 out of 844 sequences belonged to the two OTUs related to $N$. europaea and they originated from a restricted number of soil samples in 2009 (Table 1).

\section{DISTRIBUTION OF COMMUNITIES}

Operational taxonomic units of $\beta$-AOB do not appear in single populations but in communities usually composed of different OTUs. In 16 of the 90 soil samples analyzed a single OTU of $\beta$-AOB was enumerated. The number of sequences obtained from the soil samples was variable with numbers ranging from 0 to 24 , with an average of 10 . The variable number of sequences per sample or community made it difficult to compare the community structure of the $\beta$-AOB. Hence, absolute numbers of sequences were converted to percentages of OTUs in the different soil samples; samples containing less than 5 sequences were arbitrarily excluded from further analyses, as small differences in these numbers will have a large effect on the relative distribution of OTUs.

Based on a pair-wise ANOSIM, the communities present in Impoundment 23 were significantly different from those detected in Impoundment 24 (Table 3), but the difference was small $(R$ value close to zero). The comparison between years did not yield a significant time effect on the distribution of $\beta-A O B$, although the communities in 2008 were slightly different from those in 2010 (Table 3). The $\beta$-AOB community composition differed significantly between habitats with the greatest difference between the dwarf habitat and the other two (Table 3).

\section{DISCUSSION}

\section{DIFFERENCES AMONG MANGROVE HABITATS}

Overall, the communities of the $\beta$-AOB were significant different between the three mangrove habitats. Hence, the hypothesis that environmental factors that determine differences in the growth, stature, and density of Black mangroves also affect the community composition of the $\beta$-AOB was confirmed. Communities in the dwarf mangrove habitat were more different from the communities in the sparse and dense mangrove habitats and the latter two were more similar to each other. Whigham et al. (Feller et al., 2003) showed that, although all mangrove habitats were limited by nitrogen availability, this limitation was most severe in the dwarf Black mangrove habitat. The degree of nitrogen limitation was expected to also have a selective pressure on the community composition of the $\beta$-AOB (Bollmann et al., 2002).

Overall, the communities of the $\beta$-AOB were slightly different in the two impoundments (Table 3), which may have been due to differences in management (i.e., the pumping of estuarine water 
Table 2 | Operational taxonomical units (OTUs) affiliated to ammonia-oxidizing betaproteobacteria recovered from mangrove soils and their most close relatives as retrieved from BLAST search.

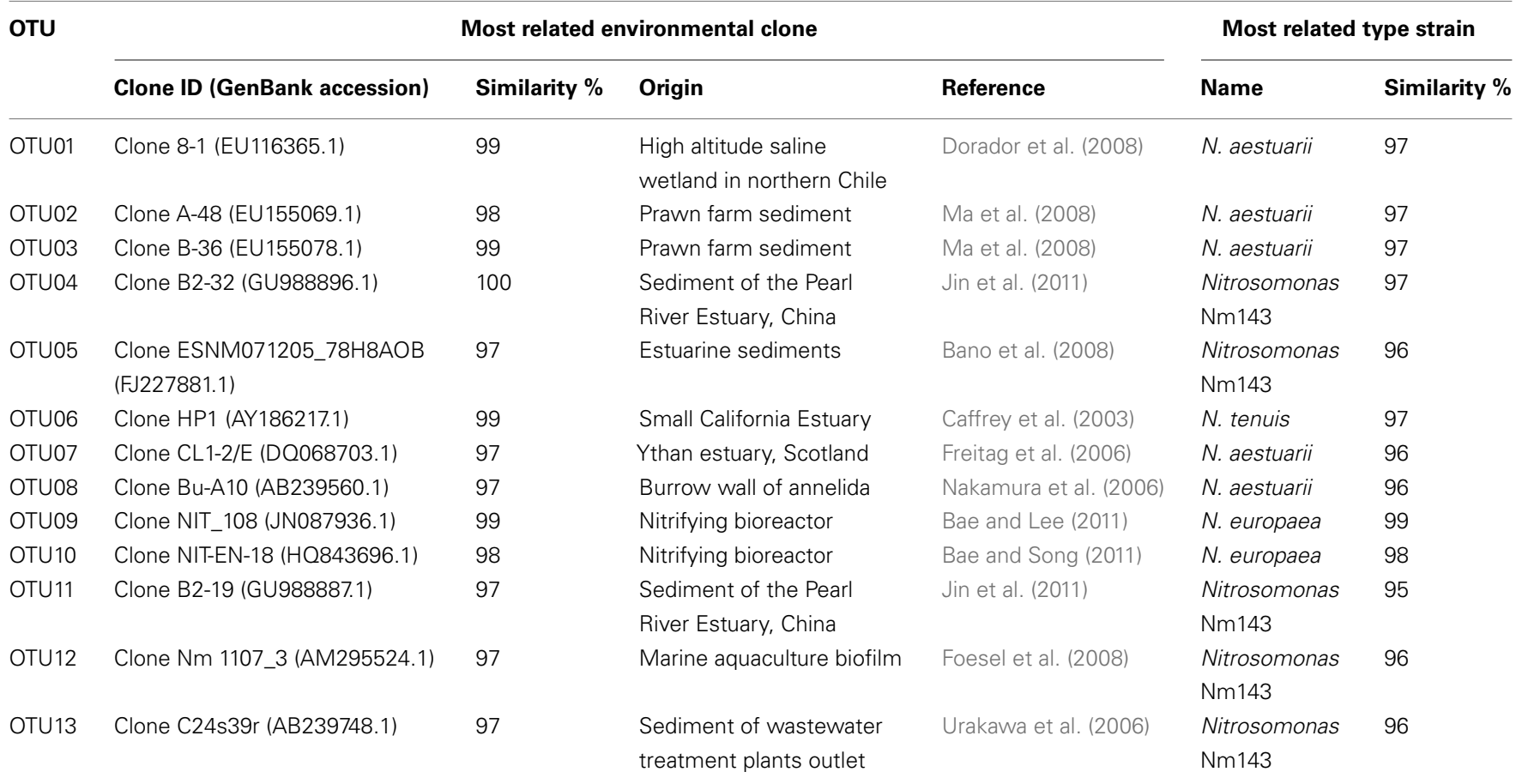

OTUs are based on 97\% mutual similarity of their 16S rRNA gene (418bp).

Table 3 | Pair-wise similarities among communities of ammoniaoxidizing betaproteobacteria as obtained from an analysis of similarity (ANOSIM) between impoundments, sampling years, and habitats of Black mangroves.

\begin{tabular}{llll}
\hline Groups & Comparison & $\boldsymbol{R}$-value & $\boldsymbol{p}$-value \\
\hline Impoundments & \#23 versus \#24 & 0.066 & 0.012 \\
Sampling years & All years & 0.045 & 0.053 \\
& 2008 versus 2009 & 0.040 & 0.102 \\
& 2008 versus 2010 & 0.061 & 0.042 \\
Mangrove habitat types & 2009 versus 2010 & 0.036 & 0.115 \\
& All types & 0.151 & 0.001 \\
& Dwarf versus sparse & 0.261 & 0.002 \\
& Dwarf versus dense & 0.118 & 0.007 \\
& Sparse versus dense & 0.076 & 0.028 \\
\hline
\end{tabular}

An R-value of zero means no difference between groups, whereas an R-value of one means an absolute difference between groups.

into Impoundment 24) or to small differences in the characteristics of the vegetation in the two impoundments. There were only salt pans, i.e., habitats with no other plant species than Black mangroves, in Impoundment 24 before the flooding of March 2009 started. In Impoundment 23 the dwarf Black mangroves were always more intermingled with other shrub plants.

\section{EFFECTS OF FLOODING}

The hypothesis that flooding of Impoundment 24 would affect the composition of the betaproteobacterial community was not unequivocally confirmed. Although the communities changed significantly between 2008 and 2010, the change between March 2009 and March 2010, a period during which estuarine water was pumped into the impoundment for several months, was not significant. A non-significant change in the community composition did occur between 2008 and 2009, during which time east Florida experienced a prolonged winter drought leading to extremely low groundwater levels in the two impoundments (M. Rains, pers. comm.). Despite the winter drought of 2008/2009, the soil moisture content at the sampling sites was not significantly different between March 2008 and March 2009. Soil moisture increased significantly between 2009 and 2010 as a result of the pumping that was initiated the exact time that we sampled the sites in 2009. At the time of our 2009 sampling, however, the impacts of the addition of water to Impoundment 24 had not yet resulted in a change in soil moisture. Independent of sampling year, we found a consistent pattern of significantly increasing soil moisture from the dwarf habitat to the dense Black mangrove habitat with intermediate soil moisture content in the sparse mangrove habitat.

One might be surprised that flooding had only a limited effect on the community composition of the $\beta$-AOB. Since flooding will limit oxygen availability in the soil, it will also repress the activity of these obligate-aerobic bacteria. Hence, changes in community composition under flooded, oxygen-restricted conditions can only be due to differences in survival between the different lineages.

In addition to the change in community composition of the $\beta$-AOB between March 2008 and 2009, the activity levels of the potential $\mathrm{AOB}$ changed over the same time period from relatively high to low and they remained low in 2010 (Figure 2). In a 
preliminary study, we had also measured relatively high PAAs in soils collected from Impoundment 24. In March 2006, the average PAAs in soils from the dwarf, sparse, and dense mangrove habitats were 15,19 , and $34 \mathrm{nMol}$ ammonia $\mathrm{h}^{-1} \mathrm{~g}^{-1}$ dry weight, respectively ( $\mathrm{P}$. Baas, unpublished results). In soils collected at the same sites in March 2007 the average PAAs were 14, 15, and $40 \mathrm{nMol}$ ammonia $\mathrm{h}^{-1} \mathrm{~g}^{-1}$ dry weight, respectively (H. J. Laanbroek, unpublished results). Hence, the values measured in 2009 and 2010 in Impoundment 24 were low compared to the three previous years; indicating that activity level and community composition of $\beta$-AOB were affected by winter drought in 2008/2009 and not by the altered management that started in March of 2009. The potential activities measured in this study were in the same range as those observed in a Rhizophora apiculata (Red mangrove) forest in Makham Bay, Thailand, by Kristensen et al. (1998).

\section{EFFECT OF SALINITY}

Although the winter drought in 2008/2009 was not reflected in a measurable change in the soil moisture content, pore water salinity had increased by an average of $72 \%$ in the three habitats (range 61-90\%) between March 2008 and 2009 (Figure 1). Following the onset of pumping of estuarine water into the impoundment in March 2009, pore water salinities decreased by an average of $43 \%$ (range 36-49\% for the three habitats) by March 2010.

The effect of salinity on the community composition of $\beta$ AOB has been observed before, but typically in estuaries where salt concentrations vary from freshwater values to marine salinities of $\sim 30 \%$. In our study, salinities measured in the soils ranged from 29 to $79 \%$ ). In marine-dominated estuarine systems, $\beta$-AOB belonging to the Nitrosospira lineage (cluster 1) dominate, but also members of the N. marina and Nitrosomonas sp. Nm143 lineages have been identified (Francis et al., 2003; Cebron et al., 2004; Bernhard et al., 2005; Freitag et al., 2006; Mosier and Francis, 2008; Sahan and Muyzer, 2008; Jin et al., 2011). Francis et al. (2003) stated that although salinity appears to play a role, no single physical or chemical parameter entirely explains the pattern of $\beta$-AOB diversity estuaries, suggesting that a combination of environmental factors may shape the overall level of $\mathrm{AOB}$ diversity in dynamic estuarine ecosystems.

In Mono Lake, a saline (68-79\%o) and alkaline ( $\mathrm{pH} 9.8)$ lake located just east of the Sierra Nevada range in northern California, Ward et al. (2000) measured a dominance of $\beta$-AOB related to N. europaea and Nitrosomonas eutropha in 1995, whereas Carini and Joye (2008) observed a dominance of Nitrosomonas halophilarelated AOB in 2002/2003. The differences in the composition of $\beta$-AOB at Mono Lake were proposed to be the result of a switch in hydrological mixing regimes resulting in reduced ammonia availabilities.

\section{DIFFERENTIAL DISTRIBUTION OF THE THREE DOMINANT LINEAGES OF $\beta$-AOB}

Based on their most close relatives, the major OTUs (i.e., OTU01, OTU04, and OTU06) identified from the impoundment soils represented the lineages N. marina, Nitrosomonas sp. Nm143, and Nitrosospira cluster 1, respectively (Table 2). OTU01 consisting of $N$. marine-related clones was relatively abundant in Impoundment 24, in 2008, especially in the dwarf habitat (Figures 3-5).
Prior to the pumping of water, the dwarf habitats in Impoundment 24 had the appearance of salt pans with no mangroves or scattered dwarf black mangroves in their center and high interstitial salt concentrations (Figure 1D). Subsequent to the initiation of flooding in Impoundment 24, the habitat was colonized by Salicornia spp. and interstitial salinities decreased. Also prior to the flooding of the impoundment, interstitial salinities were very high in all habitats, but especially in the salt pans, due to the regional drought that occurred in 2009 (Figure 1). The increase in interstitial salt concentrations in 2009 was coupled to an increase in relative numbers of OTU03 (Figure 4), which is also related to the $N$. marina lineage. The presence of the two related OTUs in the habitats with high interstitial salinities demonstrates that this lineage is more adapted to hypersaline concentrations.

OTU04 was comprised of Nitrosomonas sp. Nm143-related clones and it had a higher relative abundance in all habitats in 2010 and in the dense habitat in all 3 years that the soils were sampled (Figures 4 and 5). Soil moisture was highest in 2010 compared to 2008 and 2009 and it was also highest in the dense habitat in all 3 years (Figure 1). Therefore, it seems that members of this lineage are more adapted to higher moisture contents, which could be translated to limited oxygen availability, but also to changed accessibility of redox-sensitive nutrients such as iron and phosphate.

OTU06 consisting of Nitrosospira cluster one-related clones was relatively abundant in the sparse habitat. We were unable to identify a single soil factor or group of factors that were associated with OTU06. From an earlier study on the distribution of $\beta$-AOB in a tidal freshwater wetland (Laanbroek and Speksnijder, 2008), however, it was concluded that Nitrosospira lineages were better survivors under nutrient-limited conditions. Previous research at the current study sites has demonstrated the importance of nitrogen limitation on the growth form of black mangroves (Whigham et al., 2009). Nitrogen limitation is important in all three habitats but it may be the factor that is specifically associated with Nitrosospira cluster 1 in the sparse habitat.

\section{BETAPROTEOBACTERIA AND OTHER AMMONIA-OXIDIZING MICROBES}

A goal of our study was to determine if changes in impoundment management would alter the distribution of members of the $\beta$ AOB. Studies related to numbers and diversity of aerobic nitrifying microorganisms in mangroves are limited. Archaeal and bacterial amo $A$ genes were found in rehabilitated and pristine mangrove forests dominated by Gray (Avicennia marina) and White (A. alba) mangroves in the vicinity of Bangkok, Thailand (Wickramasinghe et al., 2009). Most AOB related sequences belonged to the lineages N. aestuarii/N. marina and Nitrosospira. No members of the ammonia-oxidizing gammaproteobacteria were detected. The numbers of bacterial amoA genes in a Kandelia obovatadominated mangrove forest in the New Territories of Hong Kong, outnumbered those of archaeal $a m o A$ genes by a factor of 512 (Li et al., 2011). The distance between individual mangrove trees had a significant effect on the community composition of the ammonia-oxidizing community of betaproteobacteria. The communities of $\beta$-AOB were grouped by the distance to the mangroves, whereas those of the archaeal amoA genes clustered 
into surface and deeper sediment groups. Most of the bacterial $a m o A$ clones identified from the mangrove forest soils belonged to clusters mostly related to the $N$. marina lineage. In a parallel analysis on the presence and diversity amoA genes of ammoniaoxidizing archaea and bacteria in polluted mangrove sediments in the Mai Po Nature Reserve of Hong Kong, the dominance of the N. marina/N. oligotropha was confirmed (Cao et al., 2011a). No Nitrosospira-related amoA genes were detected. However, when applying the $16 \mathrm{~S}$ rRNA gene, Co and co-workers detected two clusters of Nitrosospira-related sequences. The $\beta$-AOB outnumbered the AOA with 3-6 in the polluted mangrove sediments (Cao et al., 2011a).

Meyer and colleagues (Meyer et al., 2005) reported for the first time on the presence of Planctomycetes in mangrove soils. These microorganisms are capable of oxidizing ammonia under anoxic conditions (i.e., Anammox bacteria). Wickramasinghe et al. (2009) observed different phylotypes of ammonia-oxidizing Planctomycetes in rehabilitated mangrove forests in Thailand. The Anammox bacteria were related to Candidatus Scalindua brodae and Candidatus Scalindua wagneri. Again, no members of the ammonia-oxidizing gammaproteobacteria had been detected. In a study on the presence of Anammox bacteria in a mangrove forest soil near a shrimp pond in Haiphong, Vietnam, Amano et al. (2011)) observed mixed communities of Anammox bacteria dominate by phylotypes associated with Candidatus Scalindua sorokinii and Candidatus Scalindua wagneri. In the mangrove forest soils, they observed smaller numbers of sequences belonging to Candidatus Kuenenia stuttgartiensis, the phylotypes that dominated the sediment of the shrimp pond.

\section{CONCLUSION}

In this study we observed a limited diversity among the lineages of ammonia-oxidizing betaproteobacteria in the three habitats. Although the lineages were not equally distributed among the different habitats, we were unable to identify critical soil factors

\section{REFERENCES}

Alongi, D. M. (2008). Mangrove forests: resilience, protection from tsunamis, and responses to global climate change. Estuar. Coast. Shelf Sci. 76, $1-13$.

Amano, T., Yoshinaga, I., Yamagishi, T., Chu, V. T., Pham, T. T., Ueda, S., Kato, K., Sako, Y., and Suwa, Y. (2011). Contribution of anammox bacteria to benthic nitrogen cycling in a Mangrove forest and shrimp ponds, Haiphong, Vietnam. Microbes Environ. 26, 1-6.

Bae, H., and Lee, S. (2011). Failure of SHARON Process under Organic Carbon Limitation and $\mathrm{NaOH}$ Addition. GenBank.

Bae, H., and Song, J. (2011). Microbial Community Structure in Nitrifying Bioreactor. GenBank.

Bano, N., Smith, A. D., Caffrey, J. M., and Hollibaugh, J. T. (2008). Diversity of Ammonia-oxidizing Archaea

that may have been responsible for the differences. However, as the distribution of the $\beta$-AOB lineages seems to parallel the differences in plant size and density in the three habitats, focusing future efforts on revealing the factors responsible for differences in the mangroves should also provide insight in to the factors responsible for differences in the microbial communities. Based on previous studies on nutrient limitations in mangroves, potential governing factors that should be examined are nutrient (i.e., ammonium) availability, salinity, frequency of tidal inundation, degree of soil anoxia, and $\mathrm{pH}$. Such studies could well be done in microcosms containing natural mangrove soils as we have applied in a study on the effect of marine and estuarine water on the community composition of $\beta$-AOB present in a tidal freshwater wetland (Coci et al., 2005).

One might wonder whether the dynamics in environmental parameters are immediately reflected in changes in microbial community compositions that are based on DNA analyses. Inactive cells remain present in the soil when conditions change. Analysis at the RNA level would likely have given a more actual representation of the presence of active $\beta$-AOB and hence a better correlation with changing environmental conditions.

\section{ACKNOWLEDGMENTS}

We like to thank Dr. Mark Rains of the University of South Florida for the information related to the hydrology of the impounded mangrove forest in the Avalon State Park at North Hutchinson Island, St. Lucie County, FL, USA. We also want to acknowledge the help we obtained from Dr. Valery Paul, Woody Lee, and staff of the Smithsonian Marine Station at Fort Pierce. The research was supported by a grant of the Smithsonian Marine Science Network and by resources of the Smithsonian Environmental Research Center, Utrecht University, and the Netherlands Institute of Ecology. This is publication number 5252 of the Netherlands Institute of Ecology (NIOO-KNAW) and publication number 879 of the Smithsonian Marine Station.

and Earnest, L. (1997). Rehabilitation of impounded estuarine wetlands by hydrologic reconnection to the Indian River Lagoon, Florida (USA). Wetlands Ecol. Manage. 4, 93-109.

Caffrey, J. M., Harrington, N., Solem, I., and Ward, B. B. (2003). Biogeochemical processes in a small California estuary. 2. Nitrification activity, community structure and role in nitrogen budgets. Mar. Ecol. Prog. Ser. 248, 27-40.

Cao, H. L., Li, M., Dang, H. Y., and Gu, J. D. (2011a). Responses of aerobic and anaerobic ammonia/ammoniumoxidizing microorganisms to anthropogenic pollution in coastal marine environments. Methods Enzymol. 46(Pt B), 35-62.

Cao, H. L., Li, M., Hong, Y. G., and Gu, J. D. (2011b). Diversity and abundance of ammonia-oxidizing archaea and bacteria in polluted mangrove sediment. Syst. Appl. Microbiol. 34, 513-523.

Carini, S. A., and Joye, S. B. (2008). Nitrification in Mono Lake, California: activity and community composition during contrasting hydrological regimes. Limnol. Oceanogr. 53, 2546-2557.

Cebron, A., Coci, M., Garnier, J., and Laanbroek, H. J. (2004). Denaturing gradient gel electrophoretic analysis of ammonia-oxidizing bacterial community structure in the lower Seine River: impact of Paris wastewater effluents. Appl. Environ. Microbiol. 70, 6726-6737.

Coci, M., Riechmann, D., Bodelier, P. L. E., Stefani, S., Zwart, G., and Laanbroek, H. J. (2005). Effect of salinity on temporal and spatial dynamics of ammonia-oxidising bacteria from intertidal freshwater sediment. FEMS Microbiol. Ecol. 53, 359-368. 
Dorador, C., Busekow, A., Vila, I., Imhoff, J. F., and Witzel, K. P. (2008). Molecular analysis of enrichment cultures of ammonia oxidizers from the Salar de Huasco, a high altitude saline wetland in northern Chile. Extremophiles 12, 405-414.

Feller, I. C., Whigham, D. F., Mckee, K. L., and Lovelock, C. E. (2003). Nitrogen limitation of growth and nutrient dynamics in a disturbed mangrove forest, Indian River Lagoon, Florida. Oecologia 134, 405-414.

Foesel, B. U., Gieseke, A., Schwermer, C., Stief, P., Koch, L., Cytryn, E., De La Torre, J. R., Van Rijn, J., Minz, D., Drake, H. L., and Schramm, A. (2008). Nitrosomonas Nm143-like ammonia oxidizers and Nitrospira marina-like nitrite oxidizers dominate the nitrifier community in a marine aquaculture biofilm. FEMS Microbiol. Ecol. 63, 192-204.

Francis, C. A., O’Mullan, G. D., and Ward, B. B. (2003). Diversity of ammonia monooxygenase (amoA) genes across environmental gradients in Chesapeake Bay sediments. Geobiology 1, 129-140.

Freitag, T. E., Chang, L., and Prosser, J. I. (2006). Changes in the community structure and activity of betaproteobacterial ammoniaoxidizing sediment bacteria along a freshwater-marine gradient. Environ. Microbiol. 8, 684-696.

Jin, T., Zhang, T., Ye, L., Lee, O. O., Wong, Y. H., and Qian, P. Y. (2011). Diversity and quantity of ammoniaoxidizing Archaea and Bacteria in sediment of the Pearl River Estuary, China. Appl. Microbiol. Biotechnol. 90, 1137-1145.

Kowalchuk, G. A., and Stephen, J. R. (2001). Ammonia-oxidizing bacteria: a model for molecular microbial ecology. Annu. Rev. Microbiol. 55, 485-529.

Kowalchuk, G. A., Stephen, J. R., De Boer, W., Prosser, J. I., Embley, T. M., and Woldendorp, J. W. (1997). Analysis of ammonia-oxidizing bacteria of the beta subdivision of the class proteobacteria in coastal sand dunes by denaturing gradient gel electrophoresis and sequencing of PCR-amplified 16s ribosomal DNA fragments. Appl. Environ. Microbiol. 63, 1489-1497.

Kristensen, E., Jensen, M. H., Banta, G. T., Hansen, K., Holmer, M., and King, G. M. (1998). Transformation and transport of inorganic nitrogen in sediments of a southeast asian mangrove forest. Aquat. Microb. Ecol. 15, 165-175.

Laanbroek, H. J., and Speksnijder, A. G. C. L. (2008). Niche separation of ammonia-oxidizing bacteria across a tidal freshwater marsh. Environ. Microbiol. 10, 3017-3025.

Li, M., Cao, H. L., Hong, Y. G., and Gu, J. D. (2011). Spatial distribution and abundances of ammonia-oxidizing archaea (AOA) and ammoniaoxidizing bacteria (AOB) in mangrove sediments. Appl. Microbiol. Biotechnol. 89, 1243-1254.

Lovelock, C. E., and Feller, I. C. (2003). Photosynthetic performance and resource utilization of two mangrove species coexisting in a hypersaline scrub forest. Oecologia 134, 455-462.

Ma, Y., Wang, L., and Qian, L. M. (2008). Community structure of beta-proteobacterial ammoniaoxidizing bacteria in prawn farm sediment. Prog. Nat. Sci. 18, 679-684.

McCaig, A. E., Embley, T. M., and Prosser, J. I. (1994). Molecular analysis of enrichment cultures of marine ammonia oxidisers. FEMS Microbiol. Lett. 120, 363-367.

Meyer, R. L., Risgaard-Petersen, N., and Allen, D. E. (2005). Correlation between anammox activity and microscale distribution of nitrite in a subtropical mangrove sediment. Appl. Environ. Microbiol. 71, 6142-6149.

Mosier, A. C., and Francis, C. A. (2008). Relative abundance and diversity of ammonia-oxidizing archaea and bacteria in the San Francisco Bay estuary. Environ. Microbiol. 10, 3002-3016.

Nakamura, Y., Satoh, H., Kindaichi, T., and Okabe, S. (2006). Community structure, abundance, and in situ activity of nitrifying bacteria in river sediments as determined by the combined use of molecular techniques and microelectrodes.
Environ. Sci. Technol. 40, 1532-1539.

Rey, J., and Kain, T. (1991). A Guide to the Salt Marsh Impoundments of Florida. Vero Beach, FL: University of Florida, Florida Medical Entomology Laboratory.

Sahan, E., and Muyzer, G. (2008). Diversity and spatio-temporal distribution of ammonia-oxidizing archaea and bacteria in sediments of the Westerschelde estuary. FEMS Microbiol. Ecol. 64, 175-186.

Schleper, C., and Nicol, G. W. (2010). "Ammonia-oxidising archaea physiology, ecology and evolution," in Advances in Microbial Physiology, Vol. 57, ed. Robert K. Poole (Oxford: Academic Press), 1-41.

Schloss, P. D., Westcott, S. L., Ryabin, T. Hall, J. R., Hartmann, M., Hollister, E. B., Lesniewski, R. A., Oakley, B. B. Parks, D. H., Robinson, C. J., Sahl, J. W., Stres, B., Thallinger, G. G., Van Horn, D. J., and Weber, C. F. (2009). Introducing mothur: open-source, platform-independent, communitysupported software for describing and comparing microbial communities. Appl. Environ. Microbiol. 75, 7537-7541.

Stringer, C. E. (2010). Hydrologic Controls on Salinity in Mangroves and Lagoons. Doctor of Philosophy, University of South Florida, Tampa.

Stringer, C. E., Rains, M. C., Kruse, S., and Whigham, D. (2010). Controls on water levels and salinity in a Barrier Island Mangrove, Indian River Lagoon, Florida. Wetlands 30, 725-734.

Urakawa, H., Maki, H., Kawabata, S. Fujiwara, T., Ando, H., Kawai, T. Hiwatari, T., Kohata, K., and Watanabe, M. (2006). Abundance and population structure of ammoniaoxidizing bacteria that inhabit canal sediments receiving effluents from municipal wastewater treatment plants. Appl. Environ. Microbiol. 72, 6845-6850.

Verhagen, F. J. M., and Laanbroek, H. J. (1991). Competition for ammonium between nitrifying and heterotrophic bacteria in dual energy-limited chemostats. Appl. Environ. Microbiol. 57, 3255-3263.
Ward, B. B., Martino, D. P., Diaz, M. C., and Joye, S. B. (2000). Analysis of ammonia-oxidizing bacteria from hypersaline Mono Lake, California, on the basis of 16S rRNA sequences. Appl. Environ. Microbiol. 66, 2873-2881.

Whigham, D. F., Verhoeven, J. T. A., Samarkin, V., and Megonigal, P. J. (2009). Responses of Avicennia germinans (Black Mangrove) and the soil microbial community to nitrogen addition in a hypersaline wetland. Estuaries Coast 32, 926-936.

Wickramasinghe, S., Borin, M., Kotagama, S. W., Cochard, R., Anceno, A. J., and Shipin, O. V. (2009). Multi-functional pollution mitigation in a rehabilitated mangrove conservation area. Ecol. Eng. 35, 898-907.

Zhou, J. Z., Bruns, M. A., and Tiedje, J. M. (1996). DNA recovery from soils of diverse composition. Appl. Environ. Microbiol. 62, 316-322.

Conflict of Interest Statement: The authors declare that the research was conducted in the absence of any commercial or financial relationships that could be construed as a potential conflict of interest.

Received: 21 November 2011; accepted: 02 April 2012; published online: 23 April 2012.

Citation: Laanbroek HJ, Keijzer RM, Verhoeven JTA and Whigham DF (2012) The distribution of ammoniaoxidizing betaproteobacteria in stands of Black mangroves (Avicennia germinans). Front. Microbio. 3:153. doi: 10.3389/fmicb.2012.00153

This article was submitted to Frontiers in Terrestrial Microbiology, a specialty of Frontiers in Microbiology.

Copyright (c) 2012 Laanbroek, Keijzer, Verhoeven and Whigham. This is an open-access article distributed under the terms of the Creative Commons Attribution Non Commercial License, which permits non-commercial use, distribution, and reproduction in other forums, provided the original authors and source are credited. 